\title{
AUTOMATED PROJECT SCHEDULE AND INVENTORY MONITORING USING RFID
}

\author{
Geetha Kamakshi Gajamani \\ Student \\ BTCM Division \\ Civil Engineering Department \\ Indian Institute of Technology Madras, India \\ geethakamakshi@yahoo.com
}

\author{
Koshy Varghese \\ Professor \\ BTCM Division \\ Civil Engineering Department \\ Indian Institute of Technology Madras, India \\ koshy@iitm.ac.in
}

\begin{abstract}
Automated project monitoring system has the potential to be effective in controlling project performance through continuous monitoring and control of the project in real time using Automated Data Collection tools. This paper presents a system that is designed to investigate the use of RFID for automated schedule and inventory monitoring in real time. The system considers the use of precast concrete or prefabricated steel structural elements like columns, beams, floor slabs and wall panels as building components. The building components are identified in real time through automated data collection using RFID technology. This RFID technology with other application software is integrated to identify the installed component and update the project schedule in MSProject and present the as-built progress status. The 3D model of the building which is also updated is visualized in AutoCAD. The construction industry response towards the use of the developed system is also reported.
\end{abstract}

\section{KEYWORDS}

RFID, Schedule Updating, Inventory Updating, Project Monitoring

\section{INTRODUCTION}

The effective control of construction projects depends on the monitoring, in which data are collected to analyze and report the actual project performance value, based on the schedule, cost, material consumption etc., This actual value is compared with the planned value to find the variances, based on which the control measures are taken to alter the performance in the future, to meet that planned value. Thus the project performance depends on the frequency of the feedback information (monitoring) and response (control) cycle. The limitations in the present system of project monitoring due to manual data collection and the delay in the reporting cycle causes delays in the response, which results in costly and complex measures to be taken to attain the planned performance level [1]. Therefore realtime data is needed for the control. This necessitates the introduction of automated data collection techniques in construction projects for effective monitoring and control in real-time.

The precast / prefabricated components life cycle consists of the manufacturing phase, construction phase and the maintenance phase. In the manufacturing phase, the details of the components' material composition during casting or fabrication should be documented. Data of where they are stored are to be documented to identify and transport them with minimum time loss. In the construction phase, the components delivered to the site have to be inspected and stored then installed. For this process the component has to be identified, located and tracked in the construction site. The fundamental function of field materials management is to assure availability of materials when they are needed for installation and make such availability information readily accessible for crew level work planning. Thus, underlying this functionality of field 
materials management is the capability to track materials accurately and in a timely manner [2].

Finally details related to installation have to be recorded. In all these phases the real time data regarding the components identification, its location in the structure, details of installation are needed. Thus real time data is needed before and after the installation phase in case of construction projects using the precast / prefabricated components. This necessitates automated data collection not only for control but also for field material management.

One of the technologies that have been gaining significance as an automated data collection tool is the RFID technology. Radio Frequency Identification (RFID) refers to a branch of Automatic Identification Technologies in which radio frequencies are used to capture and transmit data [3].RFID technology can be used to identify and track labour / material or building components /equipment. This identification technique is used to identify and track the building components used in the site and the data collected in real time is converted using software technology for further use.

\section{RELATED WORKS USING RFID}

The NIST (2000) conducted the Comp-TRAK project, which attempted in identifying, locating and checking the position of steel members in the job site with reference to global positioning [4].It attempted automated tracking of the material from 'cradle to grave'. Akinci et al. (2002) analyzed the use of the RFID technology for tracking the precast concrete members from the manufacturer to the installation site while storing their life-cycle information [5]. Yagi et al. (2005) proposed a Concept of "parts and packets unified architecture". Information related to a product is carried by product itself and can be handled to manage the whole system [6]. Song et al. (2006) determined the feasibility of active RFID to automatically track spool pieces and read additional spools' information during delivery and receipt processes [7]. Ergen et al. (2007) conducted field tests that demonstrated the basic feasibility of an automated system which integrates RFID and GPS technologies for tracking precast pieces in a storage yard [8].
The researches and pilot studies done using RFID technology have proved that RFID technology can be used to track materials / labour / equipment / components - precast concrete or prefabricated steel.

\section{CONCEPT}

The concept is based on the use of RFID in automating the data collection, integrating it with Precast/Prefabricated components, in locating these components during the construction phase, which is shown in Figure1.

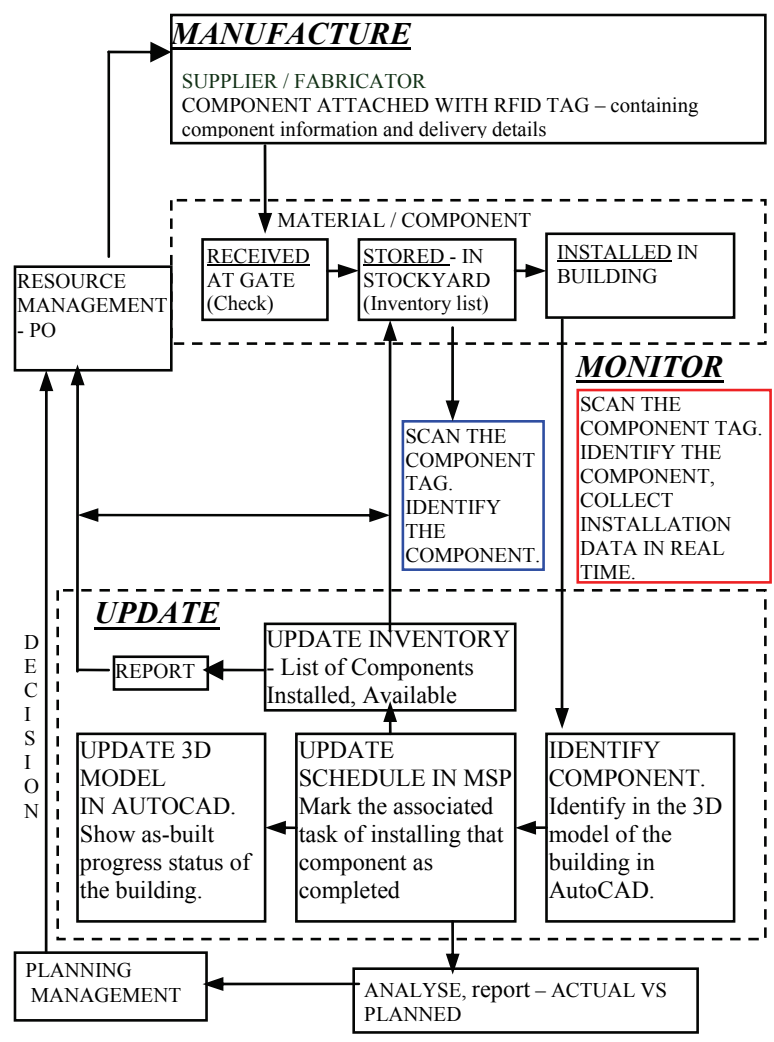

Figure 1 Concept

Based on this, the technology is utilized further to monitor the project progress.

\section{SCOPE}

The scope is limited to conducting the investigation at an experimental level, which uses scaled building model for the purpose. The RFID technology used for the system is $125 \mathrm{KHz}$ passive system, which consists of a Hand Held Wand 
Reader of read only type and tags of read only type.

The system considers the use of precast components or prefabricated components as building components. The components considered are such as the columns, beams, wall panels, floor slabs / floor decks that constitute the critical elements especially in pre-engineered buildings.

The time of scanning the component is considered as the actual completion of the associated task. This time is taken as the input for the system, and automatically entered as the actual finish time of the associated task.

The actual start time of the first task is assumed as the baseline start time of the task. The actual start time of the other tasks are assumed as the actual finish time of their corresponding predecessor task.

\section{THE SYSTEM}

The system consists of the Basic System components along with the Software Tool which forms the frame work for the System Architecture.

\subsection{The System Architecture}

Fig. 2 depicts the system architecture. The program is done in the VisualBasic6 environment. MS Excel is used for the data base; AutoCAD is used for the 3D Model drawing and MSProject for scheduling.

The tag's identification numbers that had successfully communicated with the reader is used as the input. This is got via the serial port, transmitted from the base station reader and the transferred data is imported into the program. The user interface is a VB form.

\subsection{The System Components}

The system components are,

\section{3D Model of a Building in AutoCAD}

A model of a building that is assumed to use precast / prefab components is designed. The 3D model of the building is done in AutoCAD. Each element of the model is identified with the component that could make up a precast/ prefab building.

\section{The Schedule}

The schedule is done in MSProject based on the designed 3D model.

\section{RFID technology}

\section{Required RFID Specification:}

Since the building model is done to scale, the read range required is less, i.e. within $100 \mathrm{~mm}$. The reader required is portable type for easy handling, with tags of size within 20 to $40 \mathrm{~mm}$ so that they can be accommodated on the components of the building model. Since the read range required for experiment is lesser, passive technology is suitable, which offers the required read range. Additionally the components have only to be identified and so read-only tags are opted which can be read with a handheld reader.

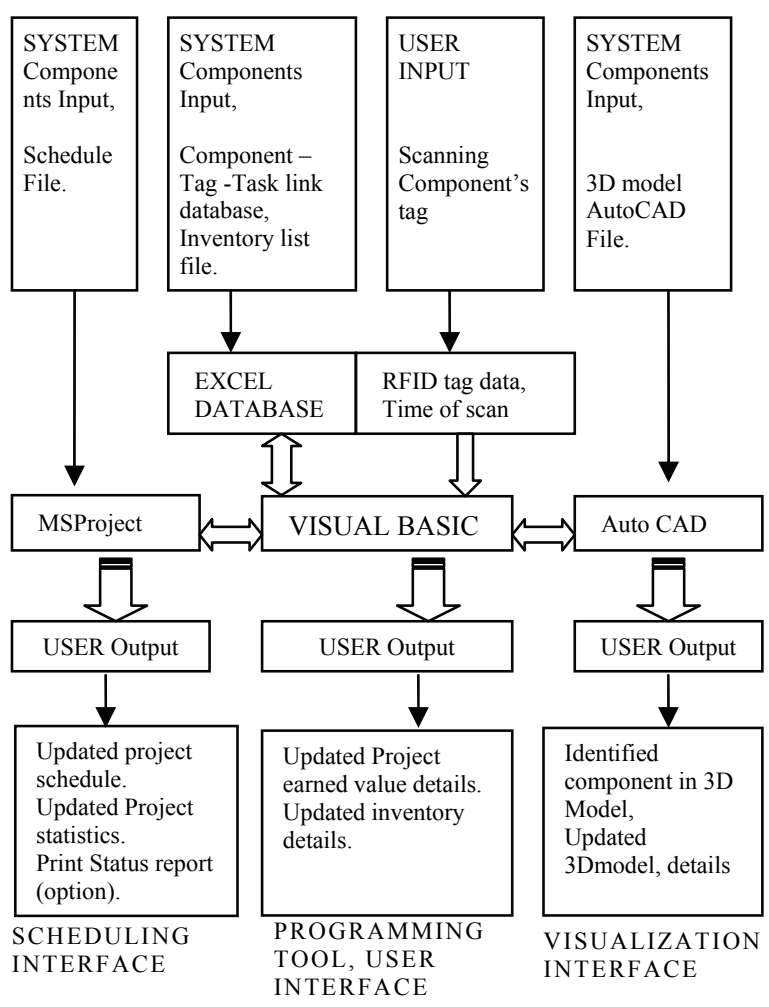

Figure 2 System Architecture

\section{Selected RFID Specification:}

RFID type: Passive System

Frequency: $125 \mathrm{KHz}$

Read Range: Approximately up to $50 \mathrm{~mm}$ 
Tag: Passive read only type tag, 30mm Flexible Disc Tag in Polyurethane transparent package and data storage capacity of 10 unique hexadecimal characters.

Reader system: The reader system consists of the 'Hand held wand reader' (read only type) of 125 $\mathrm{KHz}$ frequency, which is connected to a 'Base Station Receiver'. This Base Station Receiver is connected to the laptop or PC serial port.

\section{The Physical Model}

The model of the designed building is fabricated to scale in wood as in Fig. 3. The components of the fabricated model can be assembled or dismantled. Each component of the model is attached with a tag that has a unique ID, which is used to represent the component's ID.

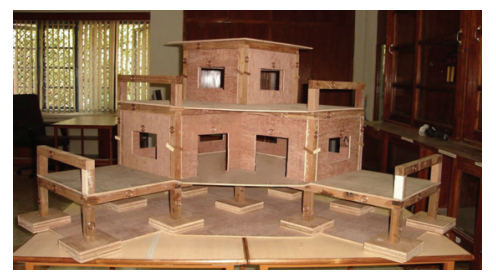

Figure 3 Fabricated Model

\section{Inventory List}

The inventory list in MSExcel contains the components under different categories that are available for assembling the building model.

\section{Software Architecture}

The architecture of the software tool is shown in Fig. 4.It consists of the input, the process and the output at macro level. The procedure is broadly divided into four phases.

In the first phase the program conducts the interrogation and the database query to authenticate the reading and retrieve the corresponding details from the database. The result of the query is displayed to the user, and used by the program for further application.

The second phase is the identification part. The program queries the database, identifies the component and displays it in the 3D model of the AutoCAD drawing file.

In third phase the program checks, is the installed component scanned already? And if the query is true then the user is asked to scan next component.
Next it checks, is the predecessor of the component completed? And if the query is true the program proceeds further, else, the user is informed that the predecessor is not completed.

The fourth phase consists of the updating of the progress details in the schedule and inventory along with the 3Dmodel drawing, based on the data that is received into the program in the first phase. Thus the details of schedule are updated in the schedule file in MSProject, the status of completion is updated in the 3Dmodel, the inventory is updated in the excel file. Finally the project progress status is presented in terms of the earned value, variances in schedule and cost and the forecasting is given in the form of TCPI

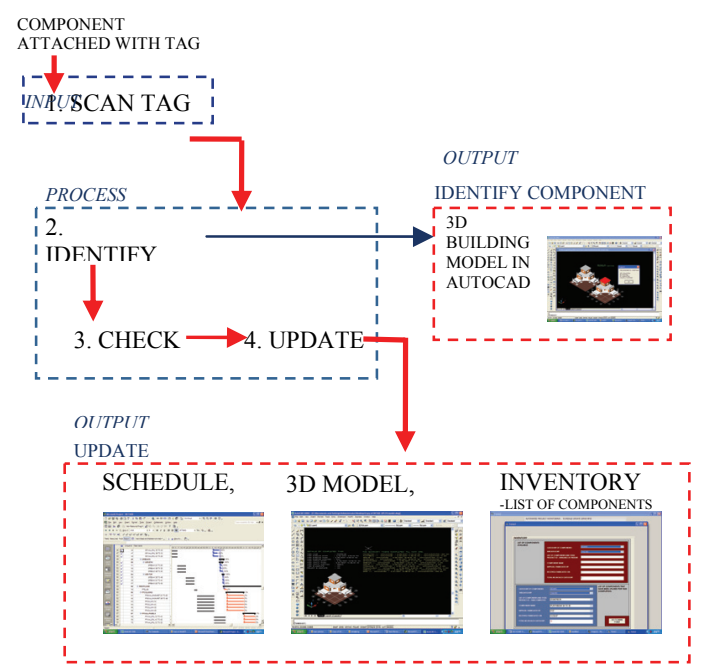

Figure 4 Phases in Software Tool

\section{SYSTEM IMPLEMENTATION}

For linking the AutoCAD 3D model components with the MSProject, the component name is assigned to the associated construction activity. Each of the component to be installed are assigned with the unique ID of a tag and also with the associated task ID which is selected from the list of tasks from the MSP file and these details are saved in an excel file. This excel file is used as the database to get the details of the component, tag and the associated task in the program.

The following steps explain the implementation procedure in detail. 
a. Capturing Data from RFID Tag: First the component's tag is scanned. When the reader is activated, it sends RF signal to the tag attached to the component, and the tags' chip returns its unique ID to the reader. This unique ID is sent to the application device.

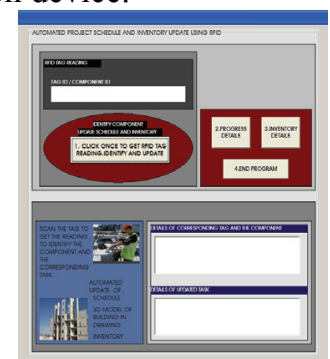

Figure 5 User Interface VB Form

b. Data Base Query and Presenting Details: The program begins following the successful reading of the tag. The clicking of a command button in the user interface which is a VB form as shown in Fig. 5, triggers the following events. The program captures the tag's data along with the date and time, authenticates tag ID and uses it to retrieve information from database about the component carrying the tag. The program identifies the component and presents the user, the details of the component and its related task details in the VB form.

c. Identifying the Component in AutoCAD 3D Model: Next, the user is presented with the AutoCAD drawing which shows the location of the identified component (where the component belongs to) in the building model as in Fig. 6. A message box gives the name of that component. In addition to that, the details like tag's ID, task's unique ID and task's baseline schedule details are also presented.

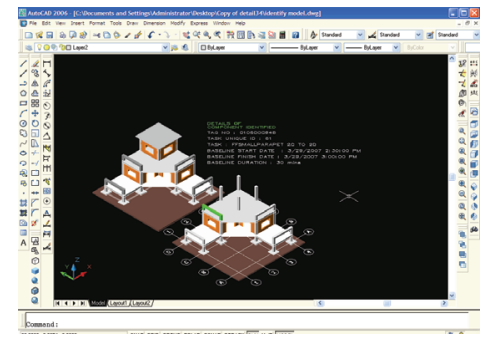

Figure 6 Visualize Identified Model

Then user is given a choice to update. The user could accept the option to update or deny and end the cycle of the program, and return to scan the next component.

d. Schedule Updating of Project in MSP File: In the next step, the schedule is updated after the program completes the checking. The program checks whether the task has already been updated or not, before opening MSP file, to avoid reentering actual finish time. If component task has already been updated, a message warns that the task has already been completed. If the task is completed and schedule has not been updated the program proceeds to check if the predecessor tasks are completed or not. If predecessor is not complete, a message warns the user that the predecessor has not been completed. Else, if the predecessor is complete, the program proceeds further to update.

The Actual finish time which is the time of scanning the components' tag and the Actual start time (assumed) which is the actual finish time of predecessor task are entered automatically into the associated task's respective fields. When the actual finish time is entered, the task is marked as $100 \%$ complete. Tracking Gantt view of network is updated automatically as in Fig.7.

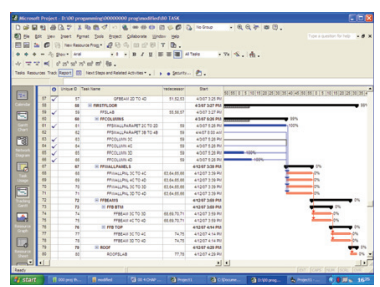

Figure 7 Updated Schedule

The user is presented with the project statistics and the option to print the project status report during the run time of the program. Finally the User is prompted to save the file. The user is also presented with the earned value method of project performance details in another VB form as in Figure 8.

\section{e. 3D Model Updating in AutoCAD File:}

The AutoCAD drawing is presented to user with the 3D Building Model which is updated based on the as-built progress. The updated 3D model view of the building is presented with the component that is installed then as in Fig .9. The program updates only after checking and confirming that the related task is updated in MSP schedule file. 
Finally the user is prompted to save the file. The file is kept updating every time when the project schedule is updated.

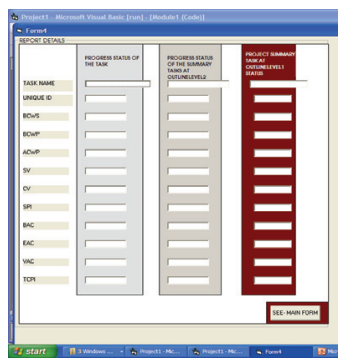

Figure 8 Project progress Details

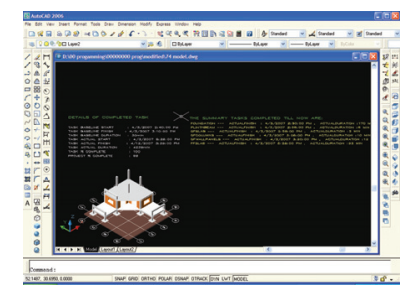

Figure 9 Updated 3D Model

f. Inventory Updating in Excel File: Updated details of the components that are available and that have been installed are presented to the user in another Form as in Fig. 10. The task is checked if it has been updated in MSP before updating the inventory file. If the query is true then the procedure for updating the inventory starts.

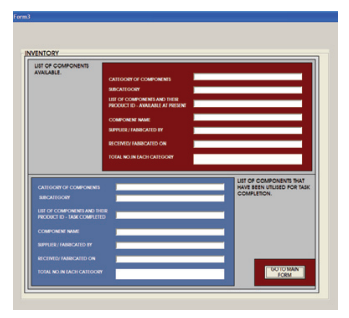

Figure 10 Inventory Update

g. End of the cycle and the program: Thus one cycle gets completed. The user is again presented with the main form to continue the program for next cycle. To begin the next cycle the user has to scan the next component and the click the command button to trigger the events. If the user wants to quit the program, the user can click the 'End' command button to invoke the event to end the program.

\section{Benefits of the System}

Direct benefits from the system can be categorized into,

$$
\begin{array}{ll}
\begin{array}{l}
\text { Data } \\
\text { collection - }
\end{array} & \begin{array}{l}
\text { Collecting Real time data. } \\
\text { Accuracy and integrity in data. }
\end{array} \\
\text { Monitoring - } & \text { Reducing the manual paper work. } \\
& \text { Faster processing. } \\
& \text { Visualizing the stage of completion. } \\
& \begin{array}{l}
\text { Saving time by reducing the } \\
\text { reporting cycle time. }
\end{array} \\
& \text { Decisions can be taken immediately. } \\
\text { Field material } & \begin{array}{l}
\text { Information regarding the inventory } \\
\text { made readily available. } \\
\text { management - }
\end{array} \\
& \begin{array}{l}
\text { Reducing time in locating } \\
\text { components. }
\end{array} \\
& \begin{array}{l}
\text { Save time in identifying where the } \\
\text { components belong to in the } \\
\text { building. }
\end{array}
\end{array}
$$

and overall process change in field operation.

\section{SYSTEM EVALUATION}

The aim of this evaluation is to establish the usefulness and utility of the System at concept and application level and to indicate where changes to the system might be needed. Typical end users from industry and experts in Civil Engineering were asked to evaluate and give comments over the system.

In overall the users have not observed any major flaw in the system and accepted the concept with minor changes to improvise the system.

The limitations that were noted are,

The tasks other than those that involve building components are not considered.

The time of actual finish of the task depends on the time of scanning the tag of the component.

The actual start of the task is assumed as the actual finish of its predecessor, for which the program could be modified to get the actual start time. 


\section{CONCLUSIONS}

The key conclusions are,

1. The System concept that is designed has demonstrated the utility of RFID technology for Automated Project Schedule and Inventory Monitoring in Construction Projects at an experimental level and thus the use of the technology in automated project monitoring along with material management in construction projects.

2. The System's architecture that is developed has the functionality which is required for utilizing the automated data collection technique using RFID with other application software, for the proposed concept.

3. The system concept developed is useful for pre-engineered construction, since the component could be tracked through the supply chain which has more advantages of combining, site material management along with monitoring project progress and performance control and with added advantage of giving information for maintenance, when read/write tags with high storage capacity are used. Thus usage of this system in pre-engineered structures construction offers the advantage of the system being both proactive and passive to enhance the total project performance. Hence, the designed system would be more suitable for pre-engineered structures than in-situ construction.

4. The limitation of using read-only tags is that the unique ID of each tag has to be linked to a data base to present other details. The passive tags read range was adequate for this system at experimental level. At implementation level, the RFID technology selected could preferably have read/ write tags along with $\mathrm{read} /$ write hand held reader, so the data can be directly written to it and utilized directly into the program and RFID technology which offer longer read range is preferable.

In Indian context, the awareness is increasing towards the use and benefits of the technology in construction for identifying components and storing their information in sites where bulk engineered materials are used. In future the new developments and thus the reducing cost of this technology could lead to increasing automation in data collection for field material management and project monitoring in real-time with reduction in cost of generating it.

\section{REFERENCES}

[1] Navon, R., and Goldschmidt, E. (2002) Monitoring labor inputs: automated-datacollection model and enabling technologies. Automation in Construction, 12, 185- 199.

[2] Song, J., Haas, C. T., Caldas, C., Ergen, E. Akinci, B. (2006).Automating the task of tracking the delivery and receipt of fabricated pipe spools in industrial projects. Automation in Construction , $15,166-177$.

[3] Jaselskis, E. J., and El-Misalami, T. (2003) Implementing Radio Frequency Identification in the Construction Process, Journal of Construction Engineering and Management, 129 (6), 680-688.

[4] Furlani, K. M., and Pfeffer, L. E. (2000) Automated tracking of structural steel members at the Construction site, Automation and Robotics in Construction XVII, Symposium Proceedings, (ISARC 2000), Taipei, Taiwan, 1201-1206.

[5] Akinci, B., Patton, M., and Ergen, E. (2002) Utilizing Radio Frequency Identification on Precast Concrete Components - Supplier's Perspective, The Nineteenth International Symposium on Automation and Robotics in Construction (ISARC 2002), Washington, DC USA, 381-386.

[6] Yagi, J., Arai, E. and Arai, T. (2005) Parts and packets unification radio frequency identification application for construction, Automation in Construction, 14(4), 477-490.

[8] Ergen, E., Akinci, B., Sacks, R. (2007) Tracking and locating components in a precast storage yard utilizing radio frequency identification technology and GPS, Automation in Construction, 163, 354-367. 